\title{
The Model of the Formation of Professional Training of Future Social Pedagogy Teachers in the Conditions of the University
}

\author{
G. Menlibekova ${ }^{1}$, E. Zhumankulova ${ }^{1}$, A. Kurmankulov ${ }^{1}$, S. Ybray ${ }^{1}$, K. Balazhanova ${ }^{2}$ and \\ Tussupbekova Gulmira,*
}

\author{
${ }^{1}$ Department of Social Pedagogy and Self-Education, Eurasian National University. L.N. Gumilev, Kazakhstan \\ ${ }^{2}$ Department on Academic Issues of the Kazakh State Women's Teacher Training University, Kazakhstan
}

\begin{abstract}
Scientific and technical progress in era of globalization, as well as socio-economic changes occurring in the global world requires the enhancement in the field of science, education, and culture also lead to the innovations on pedagogical science, modern school, and the development of the teacher personality. The school faces the task of forming a comprehensive and harmoniously developed personality. Along with this, the vocational orientation of the student's personality already at the school level becomes most relevant, especially with the introduction of a 12-year education at school

Among all above mentioned, a special place is given to a social pedagogue's personality, since his professional activity acquires qualitatively new characteristics. Social pedagogue is a link between the school and other institutions, between parents and students, and can carry out their work in multifunctional areas such as socio-pedagogical, psychologicalpedagogical, socio-legal and socio-economic sphere. Social pedagogue should also assist students in the professional orientation to develop themselves in competitive environment.

This research aims to analyze the formation of professional training of future social pedagogy teachers in the conditions of the University. And in order to achieve this goal to do some tasks. We need to describe the process of professional training of teachers and do research on its condition at the university level.

All these areas contain various aspects of the activity, and the preparation of future social teachers at the university level should be systematic, practice-oriented, and carried out at the very early stages of preparation at the University. Accordingly, the requirements for the quality of training should also change.
\end{abstract}

Keywords: Model, formation, professional, training, future, social, pedagogy, teachers, University.

\section{INTRODUCTION}

Teacher training requires the formation of his methodological reflection, the ability to navigate modern scientific concepts, assessing the level and limits of their professional competence adequately, and seeing opportunities to increase their personal potential. At the same time, the development of higher education in recent decades has led to a contradictory situation in teachers' training. On the one hand, there is a network of pedagogical educational institutions (pedagogical institutes and pedagogical universities based on them); on the other hand, classical universities (including newly formed on the basis of a number of pedagogical institutes and universities in recent years) are traditionally engaged in teacher training. The transformation of the pedagogical University into a classical one leads to the fact that the classical University often becomes the only higher education institution that trains teachers in a number of general subjects for the educational complex of the region, and, consequently, the teachers' detachment

*Address correspondence to this author at the Kazakh State National University of Al-Farabi, Almaty, Kazakhstan; Tel: +77073851878;

E-mail: zhanat2006@mail.ru will be filled with the graduates of the University. The modern teacher is a bright, creative person, possessing new pedagogical technologies, the art of communication. The nature of modern pedagogical activity requires new thinking, which values are: the priority of individual thinking, self-development, selfstudy, the transition from the "knowledge" paradigm of learning to the personality-oriented paradigm.

Changes in the requirements for the training of future specialists are put at the forefront of the formation of professional mobility and the ability to adapt to rapidly changing requirements as a necessary condition for maintaining their competitiveness in the labor market. A specialist's competitiveness is largely ensured by the presence of a high level of development of professionally significant qualities. All this is not fully possible without the successful process of professional identification, professional socialization, and professional readiness of future specialists, which should be carried out in the process of professional training at the University. In this connection, the study of these processes within the framework of the preparation of social teachers in the University is becoming increasingly relevant. It should be noted that there is a close relationship between these processes 
since professional identification provides effective professional socialization, which, in turn, forms professional readiness with the work of social educators [1].

To confirm this, it is necessary to consider each process separately using modeling. We will consider the university graduate model in the specialty "Social pedagogy" and the model of preparation of the corresponding graduate.

To build a graduate model, it is necessary to apply the developed model based on the competence approach. Competence approach in the preparation of a university graduate learned in studies [2].

\section{Problem Statement}

The relevance of the studied problem is due, on the one hand, to the requirements of modern society to the level of training of a specialist with the breadth and depth of knowledge not only in their subject area, but also in related areas, and on the other - to the rapid obsolescence acquired in the process of training at the University professional competencies.

\section{Research Questions}

The research question is to try to provide optimal conditions for the education of flexible and multifaceted scientific thinking, different ways of perceiving reality, creating an internal need for self-development and selfeducation of the future teacher based on fundamental education in a University.

\section{Purpose of the Study}

The aim of the research is to develop the approaches to the enhance the social education teachers at the University level and identify the basis for the formation of methodological competence of the future teachers.

\section{METHODS}

In the process of research, the following methods were used: theoretical (analysis of psychological and pedagogical literature, materials and publications of pedagogical and printed media on the problem of research, modelling); diagnostic (questioning; testing; method of tasks and tasks); empirical (the study of the experience of the organization of professional training of the teacher in the universities of the country, normative and educational documentation; pedagogical observation); experimental (ascertaining, search, training experiments).
A survey method was used in the study. The subjects were administered a questionnaire in which they were asked to answer questions related to their skills and actions. The items used in the questionnaire were prepared according to the related literature and interview results conducted with some future teachers. Descriptive and inferential analyses were conducted to get a deeper insight into the research questions. The time limit was 60 minutes for the survey.

\section{The Experimental base of the Research}

The experimental base for research is the Eurasian National University named after L. Gumilev.

\section{RESULTS AND DISCUSSION}

During the experiment to determine the level of formation of professional competencies of the teacher used the same methods as in the search experiment. Levels of development of professional skills by students were also determined by the results of a series of control sections.

To assess the effectiveness of the proposed model of formation of professional competencies of the teacher, we used the criterion that allows us to compare not the absolute average values of some values before and after the experiment, but the percentage distribution of data, which, in our opinion, is more objective.

Since we monitored the development of students' professional competencies from the I to IV course, the training experiment was divided into three stages, and the results were compared at the end of II, III, IV courses.

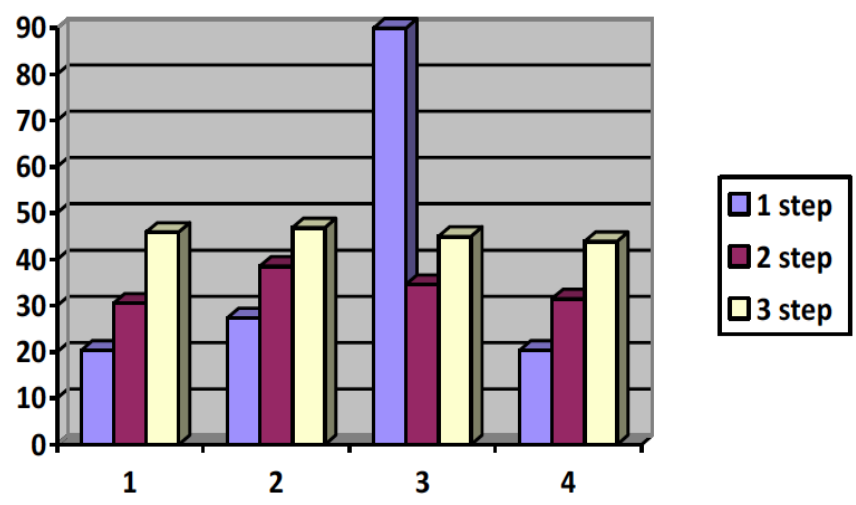

Chart 1: Monitoring the development of special professional competencies of the future teacher.

Competences: 1 - experimental, 2 - the formation of students' experimental skills, 3 - the ability to solve problems, 4 management of $t$ creativity of students. 
Boundary value $\lambda 2$ - criterion corresponding to two degrees of freedom $(m=3)$ and the probability of error tolerance of 0.01 , as well of 9.21 , which allows making a conclusion about significant changes in the level of development of professional skills and the confirmation of the purpose of the study.

Empirical research has allowed checking the efficiency of the developed model of the formation of professional competences of the future teacher.

The results of observations lead to the conclusion that the lack of readiness is due to a violation of the orientation of teachers' professional-personal attitudes, insufficient knowledge of the psychological and pedagogical age characteristics of students. This problem is most acute for university students in pedagogical practice. Among the shortcomings of professional-pedagogical training in high school of future social teachers to work is the isolation of pedagogical theory from practice, poor attention to the problem of social work, a focus on the transfer and obtaining ready-made knowledge, weak orientation to the formation of a creative approach to the future profession.

In the development of professionalism of a university graduate, the formation of such competencies of a social teacher as: a general professional and special professional is implied. Especially professional includes - methodical, psychological, educational, and auto psychological:

special competence in the field of social pedagogy. Knowledge of how to solve various situations, problems associated with a particular student;

- methodical competence in the field of social pedagogy. Knowledge of methods, methods of social assistance to students, and the ability to apply them in the process of providing social, legal, economic, and psychological support.

- psychological and pedagogical competence in the field of social pedagogy implies mastering pedagogical and psychological diagnostics, the ability to build pedagogically expedient relations with students, to carry out individual work based on the results of diagnostics; knowledge of age and developmental psychology, the psychology of interpersonal and pedagogical communication; the ability to awaken and develop in students a sustained interest in the chosen profession - schooling; auto psychological competence- a reflection of their activities, implies the ability to realize the level of their own activities, their abilities; knowledge of the ways of professional selfimprovement; self-criticism of their work; the desire for self-actualization and selfimprovement [3]

In the article, we will consider the complex areas of training of professional social teachers from the position of professionally-oriented socialization, professional identification, and professional readiness.

Consider the processes of professional socialization, professional identification, and the formation of professional readiness.

\section{Professional Socialization}

Socialization is understood in research as:

development and self-change of a person in the process of assimilation and reproduction of culture, which occurs in the interaction of a person with spontaneous, relatively directed, and purposefully created living conditions at all age stages [4]

in its content, the process of the formation of personality, which begins with the first minutes of a person's life [5]

- $\quad$ process, condition, manifestation, and result of the social formation of personality [6]

Thus, considering the process of socialization in the context of preparing future social teachers, it is necessary to study the concept of professional socialization as a process of formation and assimilation by future social teachers of the norms and values of the future profession. This process will contain a set of targeted actions, such as the entry of the future social teacher into the profession, vocational guidance, selfdetermination, and development of professional consciousness [7].

For the first time, the problem of professional socialization was identified in the late 19th and early 20th centuries. Scientists note that professional socialization is one of the key conditions for the formation of professionalism already at the university level. Professional socialization accompanies professional self-determination, awareness of the importance of professional activity, and value in the 
development of society. In the process of professional socialization, there are two conditions: firstly, the student's I-identity is identified with the I-profession, and secondly, the professional I-learner meets the modern requirements of the labor market [8].

The transition of a student to professional training opens up a qualitatively new stage in developing a professional orientation based on the transformation of the consciousness of the future social worker. Introduction to the profession becomes a necessary basis for further life, makes it meaningful. When creating an appropriate educational environment, the implementation of professional activities (practice) is understanding the profession. Emotionally, a student approaches his future profession, and he will become the main mechanism for the development of a professional. All this gives us the opportunity to distinguish several stages of forming the student's emotional attitude of the specialty "Social pedagogy" to future professional activities.

1) the formation of ideas about the future profession, and attitudes towards it;

2) filling the rational content of training, the awareness of the profession, and the conscious acceptance of the I-profession;

3) the formation of the future social teacher awareness of their professional activities, awareness of its value personally for the student, and installation on professional activities.

Thus, professional socialization contributes to understanding future professional activities and the adoption of its values and attitudes. For effective formation, it is necessary to consider professional identification as one of the professional socialization mechanisms.

In addition, in the process of preparing for professional activity, the future teacher should himself strive to master the necessary skills and abilities to work with children, cultivate a tolerance for various manifestations of children's behavior, be able to control their actions and emotions, analyze different situations, i.e., develop skills of professional-pedagogical behavior in future activities. To do this, in the pedagogical process of the University, conditions must be created that will ensure the realization of the possibilities and abilities of future teachers, aimed at the formation of knowledge and the development of skills related to the prevention and correction in the behavior of students.
Of particular interest are the reasons for the unpreparedness of social educators.

The quality of modern pedagogical education is affected by the weak practical training of future social teachers. One of the principles of didactics - the connection of theoretical education with practical activity is often violated, which leads to a decrease in the importance of professional abilities, complicates mastering general pedagogical and methodological skills, leads to confusion when solving pedagogical problems associated with various behaviors of students, in particular deviant behavior, and the extinction of professional and pedagogical interest in the future profession. While completing teaching practice, the future social pedagogue has the opportunity to test their knowledge and skills of working with adolescents with deviant behavior and, if necessary, fill in the existing gaps in theoretical training. In the conditions of the pedagogical process of school during the passage of pedagogical practice, the future teacher has a real opportunity for personal growth and awareness of the importance and necessity of the functions performed, and the positive result of applying knowledge and skills for the prevention and correction of children's behavior can serve as a powerful incentive for further study at the University. The essence and content of the concept of "professional readiness of future teachers" is revealed by researchers on the basis of the close interrelation of such philosophical categories as "consciousness" and "knowledge".

It is generally recognized in the philosophy that the category of "consciousness" is defined as the highest form of reflection of objective reality peculiar only to man, the way he relates to the world and to himself. It is precise because a person treats objects around him with understanding, with knowledge; the way he relates to the world is called consciousness. Without understanding, without knowledge, which bears within itself an objective socio-historical activity and human speech as one of the types of human activity, there is no consciousness either. By realizing their creative ideas, people transform nature, society, and thereby themselves. [9]

In the scientific researches of K.M.Kertaeva [9], the professional upbringing of the future teacher is understood as the process of the formation of professional consciousness. Based on this definition, we also consider the professional upbringing of future teachers to work with children of deviant behavior as a 
process of forming a teacher's consciousness, convinced of the need for prevention and correction of deviation among adolescents and young people.

Hence the goals of forming the professional readiness of future social teachers, among which are: the formation of a conscious readiness of a social teacher for preventive and remedial assistance to students, the stimulation of tireless scientific and practical research, the formation of professional selfawareness. One of the teacher's main tasks is the struggle for the preservation of both physical and mental health of students in accordance with the humanistic requirements for educational activities, the formation of their moral and psychological qualities, improving the personality of students [10].

Thus, the formation of the consciousness of a social teacher corresponding to professional readiness includes:

Table 1: Professional Readiness

\begin{tabular}{|c|c|}
\hline $\begin{array}{c}\text { Awareness of his } \\
\text { professional duty features }\end{array}$ & $\begin{array}{c}\text { professional activity through the } \\
\text { assimilation of theoretical } \\
\text { knowledge of attribution in the } \\
\text { period of teaching practice }\end{array}$ \\
\hline $\begin{array}{c}\text { Impact on his consciousness } \\
\text { of rational knowledge }\end{array}$ & $\begin{array}{c}\text { the formation of self- } \\
\text { consciousness }\end{array}$ \\
\hline $\begin{array}{c}\text { transformation of self- } \\
\text { consciousness into } \\
\text { professional persuasion }\end{array}$ & $\begin{array}{c}\text { regulating and normalizing } \\
\text { behavior of a teacher and } \\
\text { facilitating it }\end{array}$ \\
\hline
\end{tabular}

\section{CONCLUSION}

At the present stage, the training of future specialists in the Republic of Kazakhstan is based on the European qualification framework, the national qualification framework, and the sectoral qualification framework. On their basis, a professional standard has been developed, which, along with the state general educational standard, are key regulatory documents on which the educational program is built. The personalactivity approach in the preparation of social pedagogues is a fundamental methodological concept based on the requirement that learning should be based on considering the student's individuality when preparing for a future profession [11].

The competence approach, as one of the important methodologies in training future specialists, involves organizing and filling the educational space for training future specialists with the necessary knowledge. This approach leads to the development of a professional and a motivational component that includes the goals, values, and motives of the professional activities of future social teachers [12].

The transition to the new content of education and to the requirements of the labor market, we should be aware that the content of the vocational education process at the University should include professional socialization, professional identification, and professional readiness. Professionalism consists of student's self-knowledge, at the initial stage and the assimilation of theoretical knowledge, at the second stage and theoretical knowledge as a methodology of self-awareness at the third stage [13].

The fundamental training in the field of education, which receives a graduate of the classical University, allows you to approach the problem of professional training of the future teacher from other positions than in the pedagogical University. It is classical universities with their fundamental nature of education that are able to prepare teachers of a new type, who deeply and professionally know the relevant field of science, who have a personal interest in its certain sections, who are able not only to solve but also to set new tasks that can bring a creative direction to school and help students in mastering the methods of scientific research. The epistemological aspect of fundamental education - the development of methodology and the acquisition of knowledge skills - allows a University graduate to successfully navigate in any new environment and provides the opportunity to develop a variety of training options in one basic education.

\section{ACKNOWLEDGEMENT}

None.

\section{REFERENCES}

[1] Zinchenko V. Large psychological dictionary. ed Meshcheryakova B. AST; AST-Moscow; Prime Eurosign; Moscow; St. Petersburg 2008.

[2] Burdina EI, Torpishcheva RSh. Competence-based approach in the system of training professional translators. PSU Bulletin 2011; 2: 63-68.

[3] Vvedensky VN. Modeling the professional competence of the teacher. Pedagogy 2012; 10: 11-14.

[4] Vitvitskaya SS. Competence-based approach in building a model-professiogrammy Master of Education. // Vector science Talatyinsky State University: A series of pedagogy and psychology 2012; 4(11): 45-48.

[5] Zaitseva AA. Formation of professional identity in students of the biometrics profession. dis. Candidate of Sciences 2018; p. 194.

[6] Zeer E, Symanyuk E. Competence approach in the modernization of vocational education. Higher education in Russia 2005; 4: 23-30. 
[7] Zimnyaya IA. Key competencies as an effective target basis of a competence-based approach in education. Rector of the University 2005; 6: 13-29.

[8] Ivanov DI, Mitrofanov KR, Sokolova OV. Competence approach in education. Problems. Concepts, Instructions. M.: APK and PRO, 2003; p. 101.

[9] Kertaeva KM. Basics of pedagogical deontology. Textbook. KMKertaeva. Pavlodar. KEREKU 2009; p. 286.

[10] Klimov EA. Introduction to the psychology of labor. Textbook for universities. M.: "Culture and Sport", YUNITI 1998; p. 350 .
[11] Levitan KN. Labor psychology. Tutorial. UCHPEDGIZ 1963; p. 208.

[12] Mardahaev LV. Human socialization as a socio-pedagogical process. Pedagogical education and science 2009; 4: 21-26.

[13] Menlibekova GZH. Competence approach in social education: theory and practice. Reports of the Kazakh Academy of Education 2012; 3-4: 23-28.

Received on 03-08-2020

Accepted on 28-08-2020

Published on 14-09-2020

DOI: https://doi.org/10.6000/2292-2598.2020.08.03.34

(C) 2020 Menlibekova et al.; Licensee Lifescience Global.

This is an open access article licensed under the terms of the Creative Commons Attribution Non-Commercial License (http://creativecommons.org/licenses/by-nc/3.0/) which permits unrestricted, non-commercial use, distribution and reproduction in any medium, provided the work is properly cited. 